\title{
Endoscopic retrograde cholangiopancreatography in patients with roux-en-Y anatomy
}

\author{
Jason B. Samarasena', Ninh T. Nguyen², John G. Lee' \\ 'Division of Gastroenterology, University of California-Irvine, Orange, California; ${ }^{2}$ Department of Surgery, University of California-Irvine, Orange, California
}

Key words: Bariatric, duodenoscope, Roux-en-Y anatomy, laparoscopic-assisted

\begin{abstract}
Abbreviations: ERCP, endoscopic retrograde cholangiopancreatography; RYGB, Roux en-Y gastric bypass; DBE, double balloon enteroscopy; LAERCP, laparoscopic assisted ERCP
\end{abstract}

\section{Introduction}

Historically, Billroth II gastrectomy was the predominant surgically altered anatomy that fostered challenging endoscopic retrograde cholangiopancreatography (ERCP) procedures. Multiple studies reported excellent ERCP success using duodenoscope and forward viewing endoscopes including gastroscope and colonoscope in patients with Billroth II anatomy. ${ }^{1-3}$ In recent years, in response to the obesity pandemic in the United States, bariatric surgery has been on the rise and Roux-en-Y gastric bypass (RYGB) has become the preferred bariatric surgical method. RYGB anatomy poses a major challenge for endoscopists when biliary or pancreatic duct access is required given the long (often $>100 \mathrm{~cm}$ ) roux limb that must be traversed in order to reach the papilla. Roux-en-Y reconstruction is also commonly performed after gastrectomy or as part of choledochojejunostomy but such patients have shorter roux limbs compared to RYGB patients. ERCP procedures in rouxen-Y anatomy are among the most technically difficult and time consuming procedures performed by Gastroenterologists.

There are a variety of strategies available for endoscopists to perform ERCP in patients with roux-en Y anatomy safely and effectively. This article reviews several of these strategies with an emphasis on those patients post Roux-en-Y gastric bypass.

\section{Duodenoscopes through the anatomic route}

In order to access the biliary or pancreatic duct in a patient with roux-en-Y anatomy via the anatomic route, the endoscope needs to be advanced from the gastrojejunostomy to the jejunojejunostomy and then advanced up the biliopancreatic (afferent) limb until the biliary or pancreatic orifice is reached. Advancement of the duodenoscope through this anatomic route to the papilla is often unsuccessful in patient with roux-en

${ }^{*}$ Correspondence to: Jason B. Samarasena; Email: jason.samarasena@gmail. com

Submitted: Jan/26/2012; Revised: Jan/28/2012; Accepted: Jan/29/2012 Previously published online: www.landesbioscience.com/journals/jig DOI: $10.4161 /$ jig.22203
Y anatomy. This was demonstrated in a study by Hintze et al which reported a success rate of $33 \%$ in reaching the papilla in patients with roux-en Y anatomy. ${ }^{4}$ Failure to reach the papilla was attributed to excessive intestinal length. In contrast, in the same study the ampulla was able to be reached in $92 \%$ of patients with Billroth II gastrojejunostomy. This underscores that the success rate of reaching the papilla in a patient with roux-en Y anatomy is largely a function of the length of intestine needed to travel in order to reach the ampulla. The major advantage, however, of using the duodenoscope is that once the ampulla is reached, ERCP can be performed with techniques similar to those used in patients with Billroth II anatomy. This is especially important in patients with a native ampulla because lack of accessories for use with the enteroscope severely limits the therapeutic capabilities of ERCP.

\section{Enteroscopes or colonoscopes through the anatomic route}

The use of a pediatric colonoscope to perform ERCP in patients with roux-en Y anatomy was first reported by Gostout and Bender in 1988. Since this time, numerous reports of using enteroscopes or colonoscopes to reach the ampulla have been described. Wright et al. described 15 patients with roux-en $\mathrm{Y}$ anatomy in whom ERCP was attempted. ${ }^{6}$ In each case, with use of a forward viewing enteroscope or colonoscope, attempts were made to reach the papilla and perform ERCP. Despite reaching the papilla in 12 patients, ERCP was only successful in 2 patients using a colonoscope. The authors felt that oblique view of the papilla and lack of an elevator was responsible for the difficulties encountered with this technique (Fig. 1). Patients who have a native ampulla will probably require precut sphincterotomy for biliary access and we recommend using a short cap at the tip of the endoscope. A short cap, such as that used for endoscopic submucosal dissection, enables stabilization in front of the ampulla to facilitate sphincterotomy and can sometimes be used to "tip" the ampulla toward the endoscope to better enable cannulation. One alternative if cannulation is not feasible or unsuccessful is to place a stiff guidewire and exchange the forward viewing endoscope for a duodenoscope. Anchoring a large balloon in the stomach and 
pulling the duodenoscope to the ampulla has been also reported to work in some cases. These techniques are primarily applicable in patients with relatively short roux limbs (partial gastrectomy and choledochojejunostomy) and will not work in most patients who have RYGB, in our experience.

\section{ERCP using deep enteroscopy techniques}

\section{Double and Single Balloon Enteroscopy}

Double Balloon enteroscopy and single balloon enteroscopy have become widely available for the diagnosis and treatment of small bowel diseases. Recently, there has been an increasing number of emerging reports of double and single balloon enteroscopy techniques being used for ERCP in patients with altered surgical anatomy, especially roux-en $\mathrm{Y}$ anatomy.

The double balloon enteroscopy (DBE) procedure, introduced in 2001, is based on the combined use of a balloonloaded enteroscope and a balloon loaded overtube. ${ }^{7}$ Using the "push-and-pull" technique this enteroscope can be advanced further than a conventional enteroscope and has been used to reach the papilla via the anatomic route in patients with rouxen Y anatomy. Since originally being reported in $2005,{ }^{8}$ there have been multiple case reports and series showing the efficacy of the double balloon enteroscope in reaching the papilla and performing therapeutic techniques. A recent review of 16 studies including a total of 63 patients showed that in $83 \%$ of procedures a diagnosis was made based on findings of direct visualization of the papilla/biliodigestive anastamosis or cholangiography. ${ }^{9} \mathrm{~A}$ recent large case series of 86 procedures in 37 patients using DBE for altered anatomy ERCP showed that DBE was able to reach the biliary/pancreatic orifice in $74.1 \%$ of cases and was $87.2 \%$ successful for the planned diagnostic or therapeutic purposes when the orifice was reached..$^{10}$

The therapeutic capabilities of ERCP using a double balloon enteroscope is limited by the smaller channel size of the endoscope and the lack of available accessories. For example, only 7 french stents can be deployed using enteroscopy. The overtube, however, is useful in securing the position of the enteroscope so that it does not slide back once the ampulla is reached. The enteroscope can then be torqued within the overtube to optimize the approach for cannulation of the bile duct.' However even under the best circumstances, the endoscopic view will be oblique rather than en face. Recently, Shimatani et al reported a large case series of 103 ERCP procedures performed in 68 patients using a short double balloon enteroscope. ${ }^{11}$ The scope used in this study had a working length of $152 \mathrm{~cm}$ for which all conventional accessories could be used. Deep insertion was successful in 100/103 procedures (97\%), Cholangiogram was obtained in 98/100 procedures and treatment was successful in all 98 procedures. Complications occurred in 5/103 patients and all occurred in patients with roux-en-Y anatomy. This large series reports lower complication rates and higher procedural success rates than any other double balloon enteroscopy series in the literature and the authors recommend short double balloon enteroscopy for altered anatomy ERCP because available accessories are available. None of the patients had RYGB and thus had substantially shorter roux limbs compared to patients in the United States who undergo
RYGB; as such these results are not generalizable to patients with RYGB. In our experience, most such cases with shorter roux limbs can be performed using a conventional pediatric colonoscope, which is just as well since the short double balloon enteroscope is not commercially available in the United States.

Single balloon enteroscopy has also been utilized for ERCP in altered anatomy. Saleem et al. recently showed in a large series that after failed procedures with colonoscopes, single balloon enteroscopy was used successfully in $39 / 56$ procedures $(70 \%)$ and of the 23 procedures requiring therapeutic intervention, therapeutic success was achieved in 91\% (21/23). ${ }^{12}$ Wang et al. reported a series of 13 patients undergoing 16 procedures with nine patients having either RYGB or other long afferent limb anatomy. SBE diagnostic ERC was successful in $81.3 \%$ of procedures, and therapy was successful in $90 \%$ of cases where ERC was successful. ${ }^{13}$ Single balloon shares the drawbacks of double balloon enteroscopy with limited accessories, small channel size, lack of an elevator and oblique viewing position.

\section{Spiral or Rotational Enteroscopy}

A novel deep enteroscopy technique known as spiral or rotational enteroscopy (RoE), which uses a rotating overtube to pleat small bowel onto the enteroscope as it is advanced, has also been utilized for ERCP in altered anatomy (Fig. 2). There are several small studies reporting SE-assisted ERCP although only published in abstract form. ${ }^{14-16}$ The largest study underway to date is a US multicenter trial comparing DBE, SBE and RoE-assisted ERCP collecting retrospective data from 8 sites. In a recent abstract, this study included 129 patients who had 156 ERCPs with 27 using DBE, 45 using SBE and 57 using RoE. Enteroscopy success was defined as reaching the ampulla and ERCP success was defined as completing the intended intervention. There were 64 patients with RYGB and 45 patients with hepaticojejunostomy in this study, although the breakdown of these in each group was not stated. Enteroscopy was successful in $74 \%, 69 \%$ and $72 \%$, while ERCP success was $63 \%, 60 \%$, and $65 \%$ respectively for DBE, $\mathrm{SBE}$ and RoE. Overall, in patients with enteroscopy success $88 \%$ achieved ERCP success. ${ }^{16}$

In our experience, many patients with prior RYGB referred for ERCP do not have a clear cut diagnosis of pathology such as stone (partly due to difficulty in imaging such patients) and often carry the diagnosis of suspected sphincter dysfunction or papillary stenosis. Such patients have questionable indications for ERCP in the first place and probably have significantly higher risk of pancreatitis. A diagnostic ERCP would be inappropriate in this group of patients if they had normal anatomy, as they should undergo EUS and perhaps sphincter of Oddi manometry, neither of which is possible in patients with prior RYGB. For these reasons, we do not advocate performing ERCP using enteroscopy techniques unless the patient has a clear cut diagnosis of a stone or some treatable pathology; all others should undergo ERCP using an alternative method in our opinion.

\section{ERCP through Gastrostomy tracts}

This technique was first described by Baron and Vickers in 1998 in a patient who had undergone RYGB with frequent episodes of 
recurrent pancreatitis in whom the papilla could not be reached via the afferent limb. ${ }^{17}$ In this case, the patient underwent an open surgical Stamm gastrostomy to the distal stomach with placement of a 24F Malecot tube. Two weeks later, the patient's gastrostomy tube was removed and a pediatric forward viewing endoscope was inserted through the gastrostomy site with savary dilation of the gastrostomy stoma track up to $38 \mathrm{~F}$. Immediately after stomal dilation ERCP was performed with a duodenoscope successfully which included performing pancreatic and biliary sphincterotomy.

Following this initial report, others have reported their experience using this technique. ${ }^{18-21}$ In a recent report by Tekola et al. eleven patients with RYGB received open Stamm gastrostomy with a 32 French Malecot gastrostomy tube after which the tract was then allowed to mature for an average of 45 days. Following maturation, the tract then underwent savary dilation up to 36 french after which ERCP was performed using a duodenoscope. In all 11 patients, therapeutic ERCP was successful. Two patients had surgical site infections and one had mild bleeding after placement of the gastrostomy tube. Two patients developed postERCP pancreatitis and two patients had post-ERCP bleeding.

This technique has the advantage of gastrostomy tract

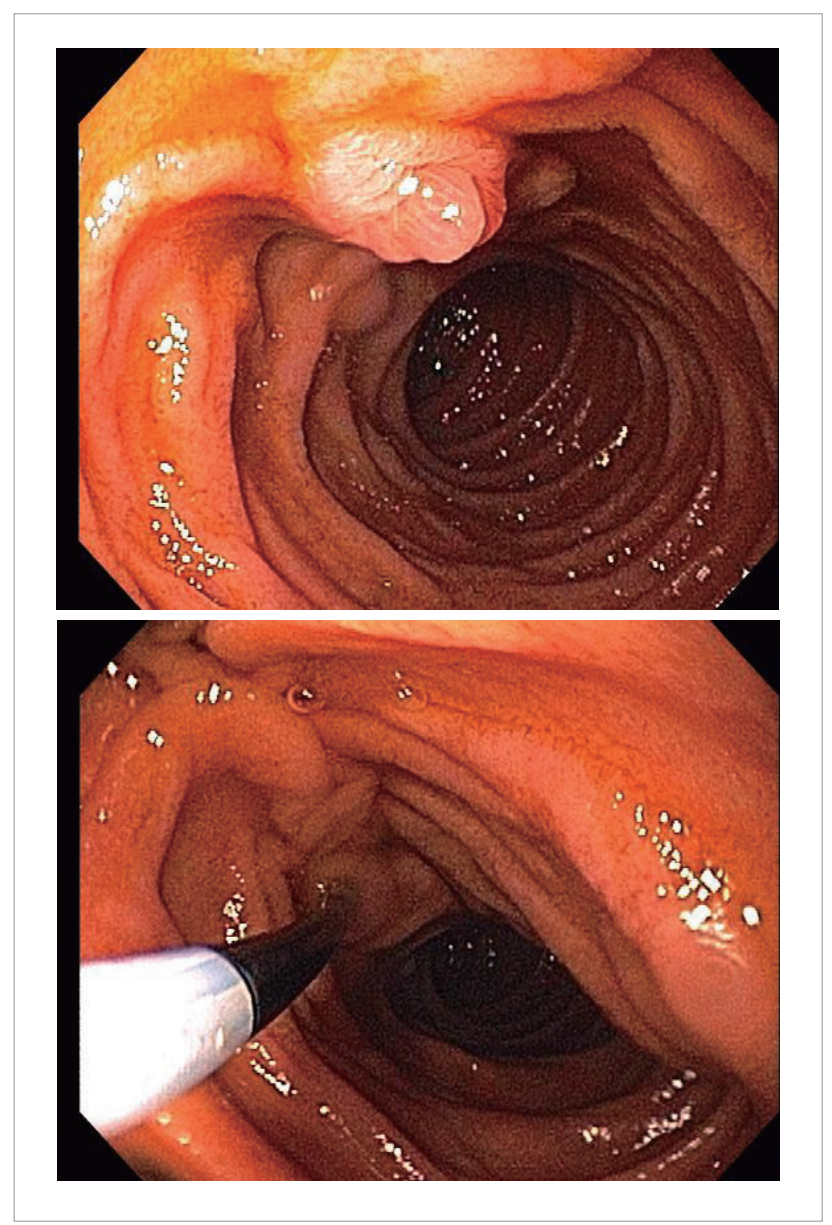

Figure 1. Oblique view of ampulla when using forward viewing endoscope (top). Biliary cannulation using Billroth II Sphinctertome (bottom). reusability for repeat ERCP in the future, which can be important when treating benign conditions. Given the ability to use a duodenoscope with a more natural position relative to the ampulla, the success rate of performing therapeutic interventions appears to be higher. The limitations of this technique include the invasive approach for placement of the gastrostomy tube which exposes the patient to the risk of post surgical complications. The other significant limitation is the significant delay between gastrostomy tube and therapeutic ERCP. Thus, this technique can only be reserved for elective ERCP in stable patients that have failed attempts with other endoscopic techniques.

\section{Laparoscopic-assisted ERCP}

An alternate transgastric approach involves the creation of a gastrotomy in the excluded gastric remnant using laparoscopy. Once access is achieved, the endoscopist inserts the duodenoscope through a $15 \mathrm{~mm}$ trocar while under laparoscopic observation (Fig. 3). The duodenoscope is passed to the second portion and ERCP performed. This technique has been reported by several investigators. ${ }^{22-27}$ One recent series by Bertin et al. described 22 cases of laparoscopic assisted ERCP (LAERCP). The indications were suspected sphincter of Oddi dysfunction in 18 patients and recurrent pancreatitis in 4 patients. Laparoscopic access to the remnant stomach was sufficient for ERCP in 21 cases and one patient required conversion to an open procedure. Pancreatic duct cannulation rate was $89 \%$ and bile duct cannulation rate was $94 \%$. There was one retroperitoneal perforation noted with pre-cut sphincterotomy of the minor papilla with no clinical repercussions.

This technique has the benefit of laparoscopic examination of the abdominal cavity and the ability to detect and treat internal hernias and to evaluate for other causes of patient symptoms. Compared to gastrostomy placement for ERCP, this technique does not require two separate procedures with maturation of the gastrostomy tract- in addition a gastrostomy tube can be

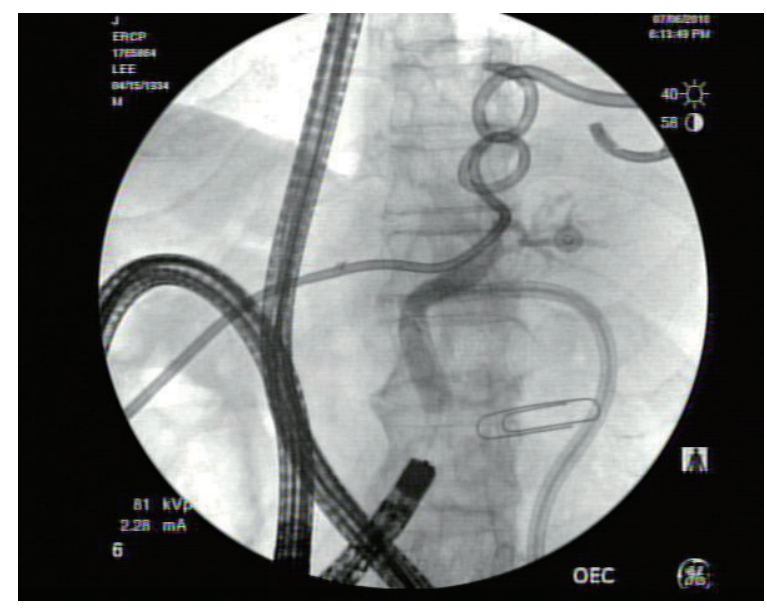

Figure 2. Fluoroscopic image of Spiral enteroscope advanced within afferent limb to ampulla in a patient with Roux-en Y Gastric Bypass 
placed after ERCP if repeat access is required for future ERCP. Although patients require laparoscopy, in our experience, they almost always can be discharged the next day unless there is a complication from the ERCP. We clearly feel that the advantages of laparoscopic assisted ERCP including laparoscopic examination, use of conventional duodenoscope and accessories far outweigh the disadvantages of laparoscopy.

Despite performing ERCP in native anatomy with a duodenoscope, transgastric ERCP can be technically challenging for several reasons. The patient is supine and the access to the stomach is limited by surgical drapes, equipment, and sterility. Passing the duodenoscope to the ampulla can be extremely difficult depending on the location of the laparoscopic access. While it should be created ideally in the proximal greater curve of the stomach, the actual location will depend on a number of factors including location and size of the gastric remnant, presence of adhesions and bleeding and surgical access. Often it is easier to create that gastrostomy near the pylorus from a surgical point of view; however doing so will make passage of the duodenoscope extremely difficult. It is not possible to reduce the duodenoscope using the transgastric approach and thus the ampulla is often further away than in usual anatomy making cutting and cannulation suboptimal. Mobilization of the stomach during laparoscopy often makes it difficult to push the endoscope as the entire stomach may push away. The gastrostomy should be made as lateral as possible along the greater curvature for good engagement of the pylorus. Clamping of the biliopancreatic limb prevents distention of distal bowel and maintains working space for laparoscopy. ${ }^{27}$ Despite the shortcomings of transgastric ERCP, at our institution this has been very effective method for ERCP in altered anatomy with a high success rate largely due to the ability to use all standard sized accessories. Furthermore, close collaboration with our surgeons has lead to fine-tuning of this procedure such that optimal conditions can be achieved.

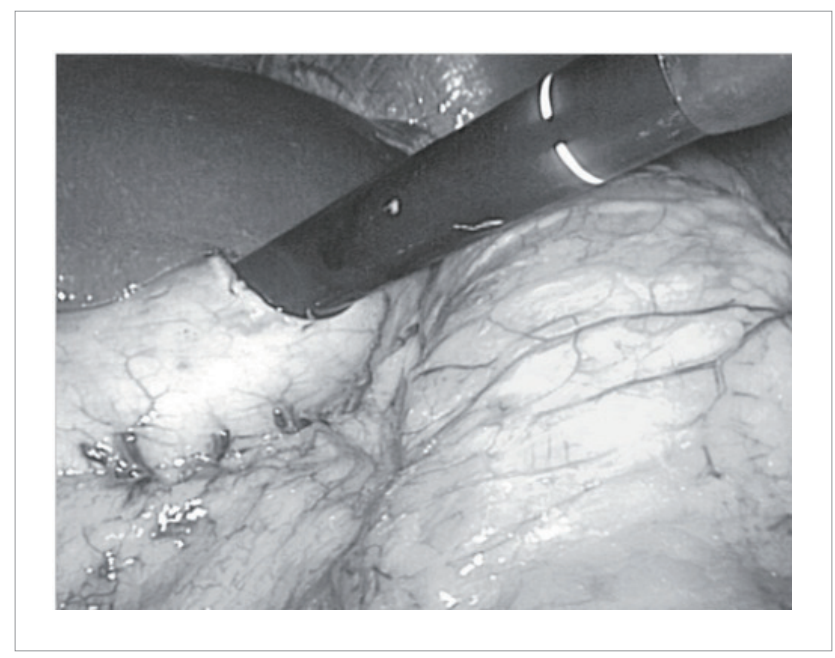

Figure 3. Laparoscopic view of the endoscope passing through a 15$\mathrm{mm}$ abdominal trocar placed into the gastric remnant for ERCP.

\section{Choosing the Best Approach}

To determine the best technique to perform ERCP in a patient with altered anatomy several factors need consideration (Table 1):

\section{Patient anatomy}

Native ampulla: For patients with native ampulla, techniques which rely on a forward viewing endoscope are suboptimal, and techniques employing a duodenoscope are preferred. The length of intestine to the papilla or pancreatic/biliary orifice via the anatomic route is the next important break in the decision tree (Fig.5 ). If the afferent limb is short $(<50 \mathrm{~cm})$ attempt at reaching the papilla with a duodenoscope is reasonable given the higher likelihood of cannulation and therapeutic success. If afferent limb is $>50 \mathrm{~cm}$ but $<100 \mathrm{~cm}$ then a pediatric colonoscope can be tried. Finally patients with RYGB should undergo LAERCP, ERCP through a gastrostomy tract or percutaneous interventions by Interventional Radiology.

Prior Spincterotomy or PE/BE anastamosis: In these patients forward viewing instruments are often adequate for performing ERCP. The length of afferent and roux limbs and the complexity of the procedure should then be used to decide which technique to employ. In patients with a short afferent limb, an enteroscope or colonoscope can be used, if the duodenoscope is unable to be advanced to the papilla. In patients with long afferent limbs, deep enteroscopy techniques can be employed with high success in reaching the papilla. Available accessories are really only useful for the most rudimentary therapies such as removing small stones. Patients who need stenting, lithotripsy, or any complex therapies should undergo LAERCP or ERCP through a gastrostomy tract with use of conventional ERCP accessories.

\section{Indication for ERCP}

Given the challenges and risks of ERCP in patients with roux-en Y

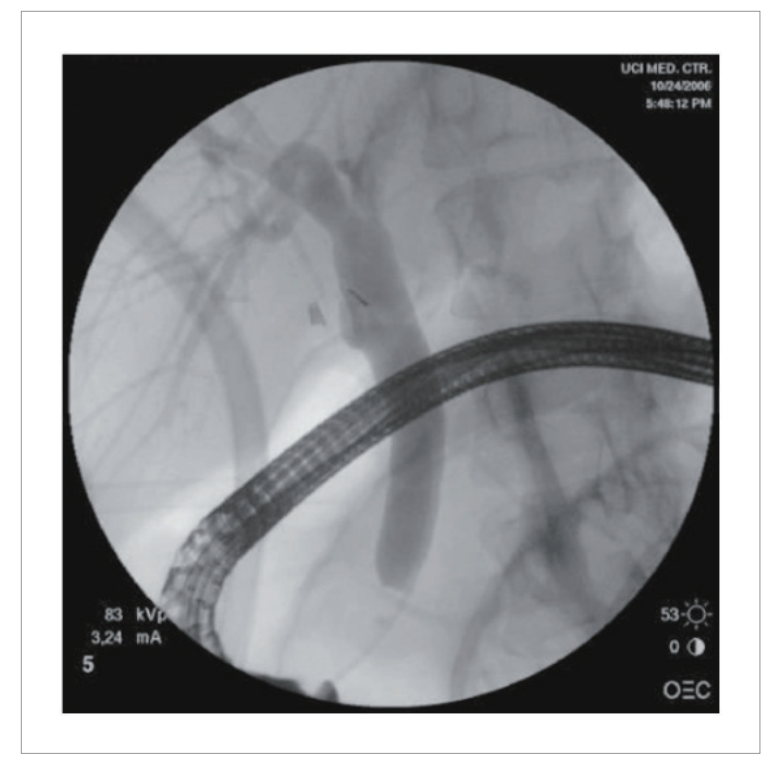

Figure 4. Cholangiogram obtained during Laparascopic assisted trans gastric ERCP in a patient with Roux-en Y gastric byass 


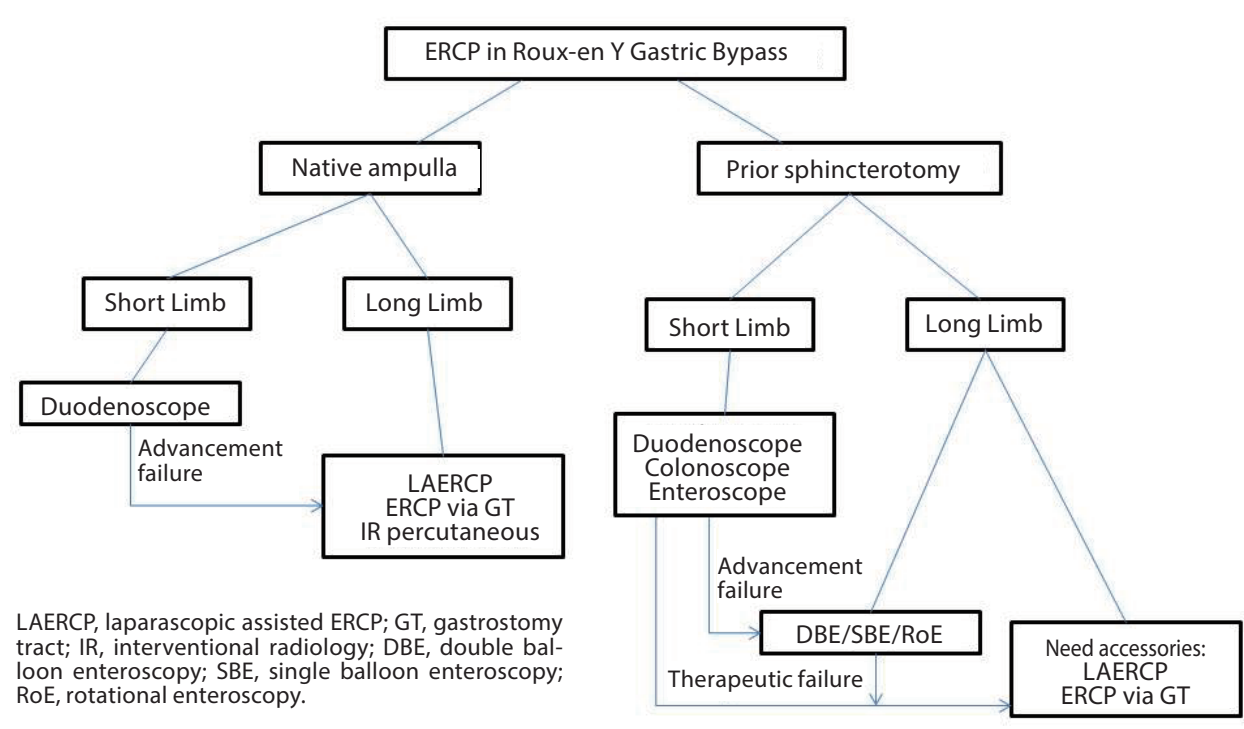

Figure 5. An approach to performing ERCP in a patient with Roux-en Y Gastric Bypass

Table 1: Comparison of different approaches for ERCP in patients with Roux-en Y anatomy

\begin{tabular}{|c|c|c|c|}
\hline Approach & Advantages & Disadvantages & Best Application \\
\hline $\begin{array}{l}\text { Duodenoscope } \\
\text { (through anatomic route) }\end{array}$ & $\begin{array}{l}\text { - Minimally invasive } \\
\text { - Side viewing facilitates cannulation of } \\
\text { native papilla } \\
\text { - Complete Instrument availability (Can } \\
\text { do high complexity interventions) }\end{array}$ & $\begin{array}{l}\text { - Often unsuccessful in long Roux } \\
\operatorname{limb}\end{array}$ & $\begin{array}{l}\text { - Native papilla } \\
\text { - Short Roux Limb }\end{array}$ \\
\hline Colonoscope/Enteroscope & - Minir & $\begin{array}{l}\text { - Forward viewing (difficult native } \\
\text { cannulation) } \\
\text { - Often unsuccessful in long roux } \\
\text { limb }\end{array}$ & $\begin{array}{l}\text { - Prior Sphincterotomy or BE/PE } \\
\text { anastamosis } \\
\text { - Short Roux Limb } \\
\text { - Low complexity interventions }\end{array}$ \\
\hline $\begin{array}{l}\text { Single/Double Balloon or } \\
\text { Spiral Enteroscope }\end{array}$ & $\begin{array}{l}\text { - Minimally invasive } \\
\text { - High success rates for reaching ampulla }\end{array}$ & $\begin{array}{l}\text { - Forward viewing (difficult native } \\
\text { cannulation) } \\
\text { - Limited availability of instruments }\end{array}$ & $\begin{array}{l}\text { - Prior Sphincterotomy } \\
\text { - BE/PE anastamosis } \\
\text { - Long Roux Limb } \\
\text { - Low complexity interventions }\end{array}$ \\
\hline ERCP through gastrostomy & $\begin{array}{l}\text { - Side viewing facilitates cannulation of } \\
\text { native papilla } \\
\text { - Allows for repeat procedures } \\
\text { - Complete Instrument availability }\end{array}$ & $\begin{array}{l}\text { - More Invasive than endoscopic } \\
\text { approaches }\end{array}$ & $\begin{array}{l}\text { - RYGB with native papilla } \\
\text { - When repeat procedures are } \\
\text { anticipated }\end{array}$ \\
\hline Laparoscopic assisted ERCP & $\begin{array}{l}\text { - Side viewing facilitates cannulation of } \\
\text { native papilla } \\
\text { - Complete Instrument availability } \\
\text { - Laparoscopy can diagnose/treat internal } \\
\text { hernias }\end{array}$ & $\begin{array}{l}\text { - More Invasive than endoscopic } \\
\text { approaches }\end{array}$ & $\begin{array}{l}\text { - RYGB with native papilla } \\
\text { - When Internal hernia is in the } \\
\text { differential diagnosis }\end{array}$ \\
\hline Interventional Radiology & - Less invasive than surgical approaches & $\begin{array}{l}\text { - Morbidity (pain, external drains) } \\
\text { - No access to pancreas }\end{array}$ & $\begin{array}{l}\text { - RYGB patients with acute cholangitis } \\
\text { - Poor surgical candidates }\end{array}$ \\
\hline
\end{tabular}

Adapted from Lopes et al. Gastroenterol Clin North Am 2010.28

anatomy, the reason for ERCP should be clear and the indication strong. As a result, we recommend non-invasive imaging such as Magnetic Resonance Cholangiopancreatography to evaluate for or confirm pancreaticobiliary pathology such as the presence of bile duct stones prior to attempting ERCP. We do not advocate diagnostic ERCP for patients with suspected sphincter dysfunction, papillary stenosis or pain only, at least without exhaustive evaluation and treatment to exclude other conditions. Patients should be clearly informed of the risk of pancreatitis and the likelihood that a definite diagnosis will not be made and 
that any therapy performed will be a therapeutic trial. Patients with native ampulla who have urgent indication for ERCP such as cholangitis should undergo percutaneous biliary drainage. Patients with prior sphincterotomy or choledochojejunostomy could conceivably undergo attempt at enteroscopy ERCP as long as complex stone extraction or stenting is not required since 7FR stents are not effective long term therapy for cholangitis.

\section{Assess surgical risk}

Patients at high risk for surgery or anesthesia should undergo non- endoscopic therapy. Patients with a potentially hostile abdomen (e.g., multiple prior surgeries) may not be candidate for laparoscopic access or even surgical exploration. Although enteroscopy approach is possible, one should keep in mind the inherent risk of perforation in such patients; therefore if surgery is truly not possible, then enteroscopy should probably be avoided.

\section{Additional Tips}

- Review the operative note for information on type of operation and length of limbs.

- Tattoo the afferent limb to save time during future ERCPs.

- Use a short cap when using forward viewing techniques to facilitate pre-cut sphincterotomy and other interventions.

- Complete a detailed report with accurate measurements and description of successful techniques.

- Employ local expertise and discuss cases with surgical and Interventional Radiology colleagues.

\section{References}

1. Kim MH, Lee SK, Lee MH, Myung SJ, Yoo BM, Seo DW, et al. Endoscopic retrograde cholangiopancreatography and needle-knife sphincterotomy in patients with Billroth II gastrectomy: a comparative study of the forward-viewing endoscope and the sideviewing duodenoscope. Endoscopy 1997; 29:82-5.

2. Aabakken L, Holthe B, Sandstad O, Rosseland A, Osnes M. Endoscopic pancreaticobiliary procedures in patients with a Billroth II resection: a 10-year followup study. Ital J Gastroenterol Hepatol 1998; 30:301-5.

3. Mosca S, Uomo G, Ceglia T, Galasso G, Ragozzino A, De Ritis R, et al. Endoscopic retrograde cholangiopancreatography in patients with Billroth II gastrectomy. Ital J Gastroenterol Hepatol 1998; 30: 297-300.

4. Hintze RE, Adler A, Veltzke W, Abou-Rebyeh H. Endoscopic access to the papilla of Vater for endoscopic retrograde cholangiopancreatography in patients with billroth Il or Roux-en-Y gastrojejunostomy. Endoscopy 1997; 29: 69-73.

5. Gostout CJ, Bender CE. Cholangiopancreatography, sphincterotomy, and common duct stone removal via Roux-en-Y limb enteroscopy. Gastroenterology 1988; 95: 15663

6. Wright BE, Cass OW, Freeman ML. ERCP in patients with long-limb Roux-en-Y gastrojejunostomy and intact papilla. Gastrointest Endosc 2002; 56:225-32.
7. Yamamoto H, Sekine Y, Sato Y, Higashizawa T, Miyata T, Iino S, et al. Total enteroscopy with a nonsurgical steerable double-balloon method. Gastrointest Endosc 2001; 53: 216-20

8. Sakai P, Kuga R, Safatle-Ribeiro AV, Faintuch J, Gama-Rodrigues JJ, Ishida RK, et al. Is it feasible to reach the bypassed stomach after Roux-en-Y gastric bypass for morbid obesity? The use of the double-balloon enteroscope. Endoscopy 2005; 37:566-9.

9. Koornstra JJ, Fry L, Mönkemüller K. ERCP with the balloon-assisted enteroscopy technique: a systematic review. Dig Dis 2008; 26: 324-9.

10. Raithel M, Dormann H, Naegel A, Boxberger F, Hahn EG, Neurath MF, et al. Double-balloon-enteroscopy-based endoscopic retrograde cholangiopancreatography in post-surgical patients. World J Gastroenterol 2011; 17: 2302-14.

11. Shimatani M, Matsushita M, Takaoka M, Koyabu M, Ikeura T, Kato K, et al. Effective "short" double-balloon enteroscope for diagnostic and therapeutic ERCP in patient with altered gastrointestinal anatomy: a large case series. Endoscopy 2009; 41:849-54.

12. Saleem A, Baron TH, Gostout CJ, Topazian MD, Levy MJ, Petersen BT, et al Endoscopic retrograde cholangiopancreatography using a single-balloon enteroscope in patients with altered Roux-en-Y anatomy. Endoscopy 2010; 42:656-60.

13. Wang AY, Sauer BG, Behm BW, Ramanath M, Cox DG, Ellen KL, et al. Single-balloon enteroscopy effectively enables diagnostic and therapeutic retrograde cholangiography in patients with surgically altered anatomy. Gastrointest Endosc 2010; 71:641-9.

14. Chandrasekhara V, Lennon AM, Singh V, Liang D, Okolo P, Hopkins J. ERCP using spiral enteroscopy in patients with altered gastrointestinal anatomy. Am J Gastroenterol 2009; 104: S384.

15. Akerman, P. and D. Cantero, Spiral enteroscopy-assisted ERCP in patients with long limb surgical biliary bypass. Endoscopy, 2009. 41: 872-7.

16. Shah RJ, Smolkin M, Ross AW, Kozarek RA, Howell DA, Bakis G, et al. A multicente U.S. experience of single balloon, double balloon and rotational overtube enteroscopyassisted ERCP in long limb surgical bypass patients. Gastrointest Endosc 2010; 71:AB134-5.

17. Baron TH, Vickers SM. Surgical gastrostomy placement as access for diagnostic and therapeutic ERCP. Gastrointest Endosc 1998; 48:640-1.

18. Matlock J, Ikramuddin S, Lederer H, Cass O. Bypassing the Bypass: ERCP via Gastrostomy after Bariatric Surgery. Gastrointest Endosc 2005; 61:AB98.

19. Martinez J, Guerrero L, Byers P, Lopez P, Scagnelli T, Azuaje R, et al. Endoscopic retrograde cholangiopancreatography and gastroduodenoscopy after Roux-en-Y gastric bypass. Surg Endosc 2006; 20: 1548-50.

20. Baron TH, Chahal P, Ferreira LE. ERCP via mature feeding jejunostomy tube tract in a patient with Roux-en-Y anatomy (with video). Gastrointest Endosc 2008; 68:189-91.

21. Tekola B, Wang AY, Ramanath M, Burnette B, Ellen K, Schirmer BD, et al. Percutaneous Gastrostomy Tube Placement to Perform Transgastrostomy Endoscopic Retrograde Cholangiopancreaticography in Patients with Roux-en-Y Anatomy. Dig Dis Sci 2011; 56: 3364-9.

22. Pimentel RR, Mehran A, Szomstein S, Rosenthal R. Laparoscopy-assisted transgastrostomy ERCP after bariatric surgery: case report of a novel approach. Gastrointest Endosc 2004; 59:325-8.

23. Nguyen NT, Hinojosa MW, Slone J, Lee J, Khiatani V, Wilson SE. Laparoscopic transgastric access to the biliary tree after Roux-en-Y gastric bypass. Obes Surg 2007; 17:416-9.

24. Ceppa FA, Gagné DJ, Papasavas PK, Caushaj PF. Laparoscopic transgastric endoscopy after Roux-en-Y gastric bypass. Surg Obes Relat Dis 2007: 21-4.

25. Mutignani M, Marchese M, Tringali A, Tacchino RM, Matera D, Foco M, et al Laparoscopy-assisted ERCP after biliopancreatic diversion. Obes Surg 2007; 17:251-4.

26. Lopes TL, Clements RH, Wilcox CM. Laparoscopy-assisted ERCP: experience of high-volume bariatric surgery center (with video). Gastrointest Endosc 2009:1254-9.

27. Bertin PM, Singh K, Arregui ME. Laparoscopic transgastric endoscopic retrograde cholangiopancreatography (ERCP) after gastric bypass: case series and a description of technique. Surg Endosc 2011; 25:2592-6.

28. Lopes TL, Wilcox CM. Endoscopic retrograde cholangiopancreatography in patients with Roux-en-Y anatomy. Gastroenterol Clin North Am 2010; 39:99-107. 